\title{
SIMPLE AND RAPID HPLC METHOD FOR SIMULTANEOUS QUANTIFICATION OF LEVODOPA AND CARBIDOPA IN A FAST DISINTEGRATING TABLET FORMULATION
}

\author{
SHOHREH ALIPOUR ${ }^{1,2}$, MAHSA ASEF1, FATEMEH AHMADI ${ }^{3,4}$
}

${ }^{1}$ Department of Quality Control, School of Pharmacy, Shiraz University of Medical Sciences, Shiraz, Iran, ${ }^{2}$ Pharmaceutical Sciences Research Center, Shiraz University of Medical Sciences, Shiraz, Iran, ${ }^{3}$ Department of Pharmaceutics, School of Pharmacy, Shiraz University of Medical Sciences, Shiraz, Iran, ${ }^{4}$ Research Center for Nanotechnology in Drug Delivery, Shiraz University of Medical Sciences, Shiraz, Iran Email: ahmadi_f@sums.ac.ir

Received: 06 Nov 2018, Revised and Accepted: 06 Apr 2019

\section{ABSTRACT}

Objective: Fast disintegrating tablets (FDTs) are found helpful in dysphagia (difficulty in swallowing) especially in Parkinson patients. Levodopa is still the first choice in Parkinson disease treatment and is co-administered by carbidopa for better efficacy.

Methods: In the present study, a rapid and simple isocratic Reverse Phase-High Performance Liquid Chromatography (RP-HPLC) method was developed and validated for simultaneous quantification of levodopa and carbidopa in optimized Fast Disintegrating Tablets (FDTs). The linearity, precision, accuracy, limit of detection (LOD) and limit of quantification (LOQ) of the method were determined. FDTs were prepared using direct compression, dry and wet granulation and were optimized for faster disintegration time. Tablets thickness, weight, hardness, friability, drug content and dissolution profile were also evaluated.

Results: A RP-HPLC system with C18 column and mobile phase 90:10 (v/v) phosphate buffer: methanol was used. The method linearity was found to be within the concentration range of 3.125-50 $\mu \mathrm{g} / \mathrm{ml}$ for levodopa, and 3.125-25 $\mu \mathrm{g} / \mathrm{ml}$ for carbidopa. The intra and inter-day precision and accuracy were acceptable. LOD and LOQ of levodopa-carbidopa were $0.2-0.8 \mu \mathrm{g} / \mathrm{ml}$ and $0.5-2.4 \mu \mathrm{g} / \mathrm{ml}$, respectively. The total chromatographic run time was 5 min. The optimized FDTs hardness was $3.81 \pm 0.4$ and tablets were disintegrated within 30 sec. Levodopa and carbidopa were dissolved in dissolution media within 5 min.

Conclusion: Results indicated that this method was suitable for simultaneous quantification of levodopa and carbidopa in the presence of different ingredients of a pharmaceutical solid dosage form. Therefore, this method could be applied in pharmaceutical quality control for rapid quantification of structurally similar substances with different physicochemical properties.

Keywords: High-Performance Liquid Chromatography, Levodopa, Carbidopa, Fast Disintegrating Tablets

(C) 2019 The Authors. Published by Innovare Academic Sciences Pvt Ltd. This is an open access article under the CC BY license (http://creativecommons.org/licenses/by/4.0/) DOI: http://dx.doi.org/10.22159/ijap.2019v11i3.30676

\section{INTRODUCTION}

Parkinson is a neurodegenerative disease affects dopaminergic neurons within the nigro-striatal and surrounding pathways which decreases dopamine in the central nervous system [1]. Although different drug categories have been administered to treat the Parkinson's disease, levodopa is still demonstrating the most vigorous relief from the motor signs and symptoms of disease [2]. Considering extensive metabolism in the peripheral circulation, levodopa exhibits low oral bioavailability and brain uptake. Hence, to prevent levodopa peripheral degradation and increase its concentration in the systemic circulation, levodopa is coadministered with carbidopa which is a peripheral amino acid decarboxylase inhibitor [3]. The first levodopa-carbidopa marketed product was a conventional swallowing tablet [2].

The most preferred route of administration for drug therapy is an oral route. Solid oral dosage forms such as tablets must be swallowed to release their active ingredient in gastrointestinal fluids for absorption [4,5]. Pediatric and geriatric patients have difficulty in swallowing the conventional dosage forms [6-8]. Indeed, tablets are found difficult to swallow in case of dysphagia. Dysphagia (difficulties in swallowing) which is more prevalent in Parkinson's disease [9], results in poor compliance in many of the elderly patients who use the conventional tablets [10].

In order to overcome this obstacle, fast disintegrating tablets (FDTs) have been developed which are disintegrated/dissolved/dispersed in saliva within few seconds without water $[11,12]$. FDTs seem to be suitable alternatives for conventional oral tablets because of the elimination of swallowing difficulties in the elderly in addition to achieve a rapid onset of action $[10,13]$. Another advantage of FDTs is drug absorption from the pharynx and esophagus which leads to increase bioavailability significantly greater than that observed for conventional tablet dosage forms [14].
Both organic and inorganic compounds can be analyzed in different sample types using high performance liquid chromatography (HPLC) technique. Separation and quantification of structurally similar substances with different physicochemical properties are the basis of pharmaceutical quality control. HPLC methods with several detection techniques are considered as gold standards in quality control of pharmaceutical formulations [15]. Due to the similar structure of levodopa and carbidopa, their quantification in pharmaceutical formulations is difficult. Different previous studies have focused on LC/MS and HPLC-MS/MS analytical methods for levodopa especially in biological fluids [16-18] and HPLC technique in pharmaceutical formulation quality control [19]. Simultaneous determination of levodopa and carbidopa in pharmaceutical products has been reported by RP-HPLC using fluorescence [20], and UV-visible photodiode array detector [21]. A complex gradient HPLC system has been studied for analysis of levodopa and carbidopa along with etacapone [21]. The scientific novelty of present study was to develop oral disintegrating tablets containing both levodopa and carbidopa and to establish a simple isocratic RP-HPLC method for simultaneous quantification of levodopa and carbidopa in presence of different tablet excipients.

\section{MATERIALS AND METHODS}

\section{Materials}

Levodopa, carbidopa and Avicel PH 102 were purchased from Alborz pharmaceutical company. Croscarmellose sodium and crospovidone were purchased from Sigma-Aldrich and HPLC grade methanol from Samchun (South Korea). Potassium dihydrogen phosphate Orthophosphoric acid, hydcrochloric acid (HCl), sorbitol, lactose, vanillin, aspartam and starch were purchased from Merck (Germany).

\section{HPLC analysis of levodopa and carbidopa}

HPLC apparatus equipped with UV/Vis detector (detection wavelength $280 \mathrm{~nm}$ ) was used for levodopa and carbidopa 
simultaneous assay. HPLC analysis method was developed based on previous literature with some modifications $[18,22]$. The RP-HPLC column was C18 (25× $4.6 \mathrm{~mm}$ column) and the mobile phase used was a 90:10 (v/v) phosphate buffer solution $0.5 \mathrm{M}$ : methanol. The flow rate of the mobile phase was maintained at $1.0 \mathrm{ml} / \mathrm{min}$ with a run time of $5 \mathrm{~min}$. The injection volume was set to $20 \mu \mathrm{l}[18,21,23]$.

\section{Standard solution preparation}

Stock standard solution $(0.4 \mathrm{mg} / \mathrm{ml})$ of levodopa and carbidopa were prepared by dissolving $40 \mathrm{mg}$ levodopa and carbidopa in distilled water, separately. The stock standard solution was diluted, as necessary to give five standard solutions with different concentrations of levodopa $(6.25,12.5,25,50$, and $100 \mu \mathrm{g} / \mathrm{ml})$ and carbidopa $(3.125$, $6.25,12.5,25 \mathrm{and} 50 \mu \mathrm{g} / \mathrm{ml}$ ) which were used in the construction of the calibration curve. The same volume of standard solutions of levodopa and carbidopa were mixed and standard solutions were prepared contained levodopa $(3.125,6.25,12.5,25$, and $50 \mu \mathrm{g} / \mathrm{ml})$ and carbidopa $(1.56,3.125,6.25,12.5 \mathrm{and} 25 \mu \mathrm{g} / \mathrm{ml})$, together.

\section{HPLC method validation}

\section{Specificity}

Specificity of the method was evaluated by making individual injections of sample solvent, levodopa, carbidopa and a placebo containing all tablet excipients except levodopa and carbidopa [21].

\section{Linearity}

Five series of standard solutions of levodopa and carbidopa were examined for determining the linearity of the method. All linearity solutions were injected in triplicate. \% RSD of peak response in triplicate injections for each level was calculated. Regression line of average peak areas of levodopa and carbidopa versus concentration of levodopa and carbidopa was plotted and the coefficient of correlation $r$, slope, yintercept and residual sum of squares were determined [21].

\section{Accuracy}

Accuracy was evaluated by assaying in triplicate, samples of known concentrations spiked with two different concentrations of standard solution (10 and $40 \mu \mathrm{g} / \mathrm{ml}$ ) of levodopa and carbidopa. Recovery (\%) was calculated from differences between the peak areas obtained for spiked and un-spiked solutions [21].

\section{Precision}

Repeatability (inter and intra-day precision) was evaluated by measuring area under the curve of five concentrations. Three times in a same day and on three separate days, finally five different samples at the 3.125 to $50 \mu \mathrm{g} / \mathrm{ml}$ range were analyzed under the same experimental conditions. Precision was expressed as percent of relative standard deviation [RSD (\%)][21].

\section{Sensitivity}

Limit of detection (LOD) and limit of quantification (LOQ) represents the lowest concentration of the analyte yield a signal-to-noise ratio of 3 and 10, respectively. The LOD and LOQ were determined using equations (1) and (2), Where $\sigma$ is standard deviation of Y-intercept and $S$ is the slope of the calibration curve.

$$
\begin{aligned}
& \text { Eq 1: } L O D=\frac{3.3 \delta}{\mathrm{s}} \\
& \text { Eq 2: } \mathrm{LOQ}=\frac{10 \delta}{\mathrm{s}}
\end{aligned}
$$

\section{Tablet preparation}

Different FDT formulations were prepared by direct compression and granulation-compression method using a single punch tablet press machine (Erweka, AR400, Germany). Levodopa and carbidopa amount in each tablet was set to 100 and $10 \mathrm{mg}$, respectively. Granulation solution in different formulations was sorbitol and starch $10 \%$. Granulating solution was added dropwise to the powder mixture. The obtained paste was sieved through 25 mesh and dried for $24 \mathrm{~h}$ at room temperature [24]. The superdisintegrants (croscarmellose sodium and crospovidone) in different concentrations $(11-15 \%)$ were used to develop the tablets. All the ingredients (shown in table 1) were passed through mesh no.60 and were co-ground for $5 \mathrm{~min}$. The blend of drugs and excipients was compressed using a single-punch machine to produce tablets.

\begin{tabular}{|c|c|c|c|c|c|c|c|c|c|}
\hline & F1 & F2 & F3 & F4 & F5 & F6 & F7 & F8 & F9 \\
\hline levodopa & 100 & 100 & 100 & 100 & 100 & 100 & 100 & 100 & 100 \\
\hline carbidopa & 10 & 10 & 10 & 10 & 10 & 10 & 10 & 10 & 10 \\
\hline Sorbitol & 60 & 200 & - & 100 & 200 & 100 & 200 & - & - \\
\hline Crospovidone & 50 & 50 & 50 & 50 & 50 & 50 & 50 & 50 & 50 \\
\hline Croscarmellose sodium & 50 & 50 & 50 & 50 & 50 & 50 & 50 & 50 & 50 \\
\hline Avicel PH 102 & - & - & - & - & - & - & - & 100 & 100 \\
\hline Lactose & - & - & 100 & - & - & - & - & - & - \\
\hline Vanillin & 6 & 6 & 6 & 6 & 6 & 6 & 6 & 6 & 6 \\
\hline Aspartam & 14 & 20 & 20 & 20 & 20 & 20 & 20 & 20 & 20 \\
\hline Direct Compression & + & + & - & - & - & - & - & - & - \\
\hline Intra granular disintegrant & - & - & 50 & 50 & 50 & - & - & 20 & - \\
\hline Extra granular disintegrant & - & - & 50 & 50 & 50 & 100 & 100 & 80 & 100 \\
\hline $\begin{array}{l}\text { Granulationand } \\
\text { Compression }\end{array}$ & - & - & + & + & + & + & + & + & + \\
\hline \multirow[t]{2}{*}{ Granulation solution } & - & - & Starch & Sorbitol & Starch & Sorbitol & Starch & Starch & Starch \\
\hline & & & $10 \%$ & $10 \%$ & $10 \%$ & $10 \%$ & $10 \%$ & $10 \%$ & $10 \%$ \\
\hline Total weight & 290 & 436 & 336 & 336 & 336 & 336 & 436 & 336 & 336 \\
\hline
\end{tabular}

Table 1: Composition of different formulations (amounts are in $\mathbf{m g}$ )

\section{Tablets evaluation}

\section{In vitro disintegration time}

The most important factor for quality control of FDTs is disintegration time. The tablets were positioned in the center of the petri dish containing $5 \mathrm{ml}$ of water at $25^{\circ} \mathrm{C}$ and the time required for the tablet to be completely disintegrated was noted $[25,26]$.

\section{Friability}

Twenty tablets of each formulation batch were weighed precisely and placed in the friabilator (Erweka, Germany) which was rotated 4 min at $25 \mathrm{rpm}$. Tablets were dedusted, reweighed and percentage of the weight loss in each tablet was calculated by equation 3 [25]:

$$
\text { Eq3 F=100 } \times \frac{\text { initial weight }- \text { final weight }}{\text { initial weight }}
$$

\section{Thickness and weight uniformity}

Thickness of ten tablets was measured using micrometer screw (Erweka, Germany). Twenty tablets of selected batches were selected randomly and weighed individually and all together. The weight average and the deviation percentage were calculated [25]. 


\section{Hardness}

The compression force applied diametrically to crush 6 tablets from each formulation batch was determined in newton using a hardness tester (Erweka, Germany) and the average of readings was determined [25]

\section{Drug content determination}

Randomly ten tablets were crushed in a mortar and an accurately weighed amount was transferred to $100 \mathrm{ml}$ volumetric flask and diluted by phosphate buffer pH 6.8 and stirred for $1 \mathrm{~h}$. The mixtures were centrifuged and appropriate dilutions were examined for drug content using validated HPLC method [25].

\section{In vitro dissolution profile}

In vitro dissolution time of optimized tablet, formulation was examined in dissolution apparatus type-II (Erweka, DT70, Germany) which stirred at $50 \mathrm{rpm}$ in $900 \mathrm{ml} 0.1 \mathrm{~N} \mathrm{HCl}$ as dissolution media at $37 \pm 0.50{ }^{\circ} \mathrm{C}$. Samples $(5 \mathrm{ml})$ were withdrawn at specified time intervals and analyzed for drug content using the validated HPLC method. The volume withdrawn at each interval was immediately replaced with an equal fresh quantity of the dissolution medium $[25,27]$

\section{Statistical analysis}

All statistical analysis of the presented study was performed using SPSS $^{\circledR}$ software 16. The one way ANOVA test was used to compare results. The p-value $<0.05$ showed significant differences.
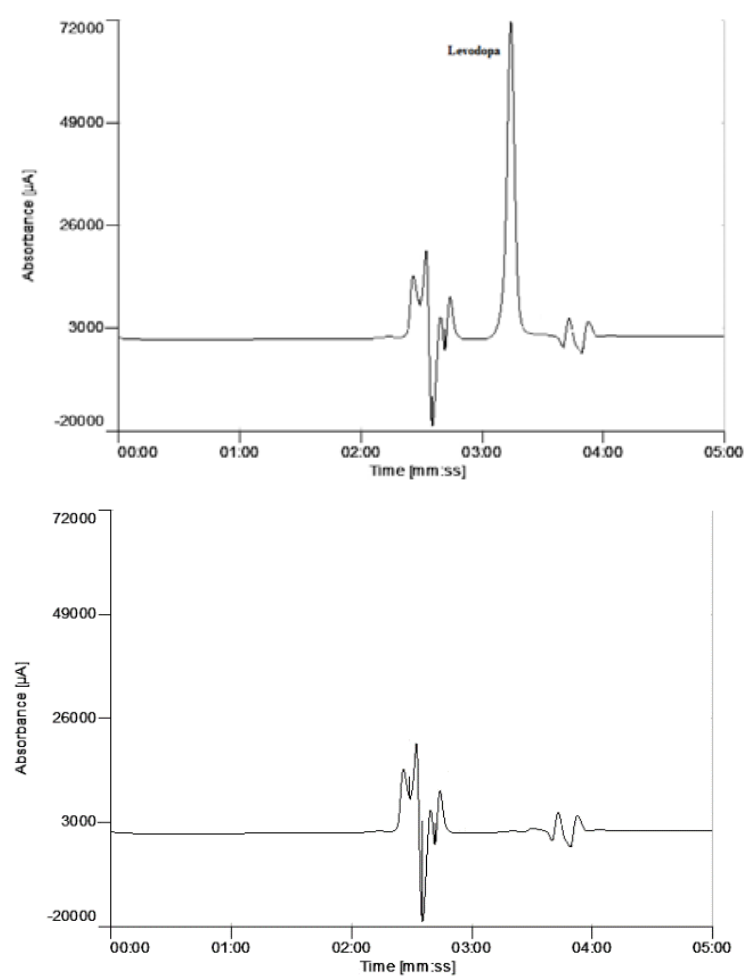

\section{RESULTS AND DISCUSSION}

\section{HPLC analysis of levodopa and carbidopa}

The most challenging issue in HPLC analysis of this study was to separate and specify levodopa and carbidopa peaks from tablet excipients. A simple and efficient HPLC method for simultaneous determination of levodopa and carbidopa in the presence of different excipients was developed. As reported in previous studies, levodopa and carbidopa analysis in the liquid formulation have been performed before, using C18 column and acetate buffer in $\mathrm{pH} 4$ which eluted levodopa and carbidopa at retention times of 5 and 11 min [22]. Another study reports simultaneous levodopa and carbidopa analysis using a gradient program and UV-visible photodiode array detector as a detecting instrument [21].

However, in the present study, a simple isocratic mobile phase containing 90:10 $(\% \mathrm{v} / \mathrm{v})$ phosphate buffer solution $0.5 \mathrm{M}$ : methanol in accompanying with a UV-visible detector separated the analytes completely. As seen in chromatogram in fig. 1, levodopa and carbidopa peaks were appeared at 3.5 and 4 min separately, while their retention times in mixture solution changed to 3 and $3.5 \mathrm{~min}$ with no interference of tablet excipients. Levodopa and carbidopa were separated completely and showed suitable retention times and good resolution compared to the previous literature reports. The total run time was $5 \mathrm{~min}$. that indicates a reduction in running time compared to most analytical methods.
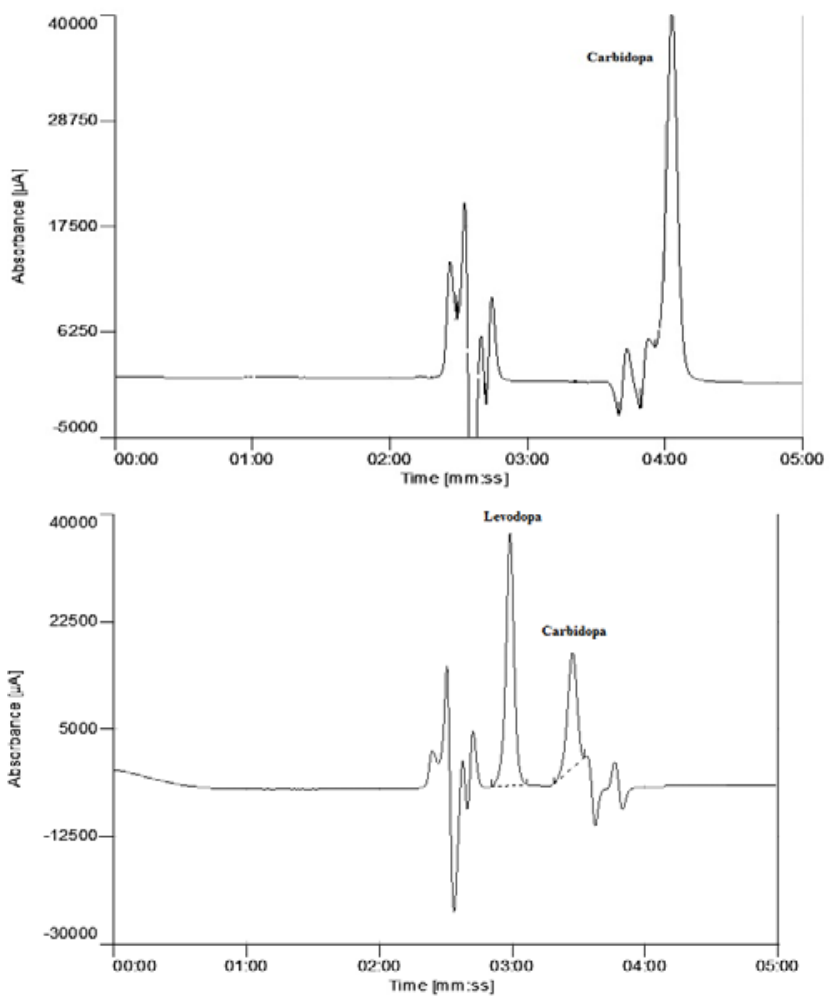

Fig. 1: Chromatograms of levodopa and carbidopa (up), blank tablet (down, left,) extracted levodopa and carbidopa from tablet (down, right)

\section{HPLC calibration}

Calibration curves of both drugs were constructed separately in the expected concentrations range from 3.125 to $50 \mu \mathrm{g} / \mathrm{ml}$ for levodopa and 3.125 to $25 \mu \mathrm{g} / \mathrm{ml}$ for carbidopa (fig. 2).

\section{HPLC method validation}

The levodopa and carbidopa chromatographic peaks were free from interference in all cases. Chromatograms of levodopa and carbidopa standard solutions and placebo tablet are shown in fig. 1 . As it is seen no interfering peak was observed at the retention time of levodopa and carbidopa.

The analysis method was validated for specificity, linearity, precision and accuracy. Results indicated that the method is suitable for simultaneous quantification of levodopa and carbidopa in a solid pharmaceutical formulation. The peak area of levodopa and carbidopa exhibited linear relationship with their concentrations. Correlation coefficient $\left(\mathrm{r}^{2}\right)$ of the standard curve indicated a linear relationship at the selected range for levodopa (0.9997) and carbidopa (0.9993). The intra-and inter-day 
variation of the method were determined using five replicate injections at five different concentrations. These solutions were prepared and analyzed on the same day and on three different days, respectively. Results indicated $98 \%$ and $97 \%$ intra-day and inter-day precision for levodopa and carbidopa respectively. Accuracy of the method for determination of levodopa and carbidopa was 96 and 97\%, respectively.
These data (table 2) indicate a considerable degree of precision and reproducibility of the method during different analytical runs. The LOD and LOQ for levodopa and carbidopa were determined using Equations 1 and 2. As it is seen in table 2, the LOQ obtained for the present method was lower than previous reports for both levodopa $(3.11 \mu \mathrm{g} / \mathrm{ml})$ and carbidopa $(0.78 \mu \mathrm{g} / \mathrm{ml})[22]$.
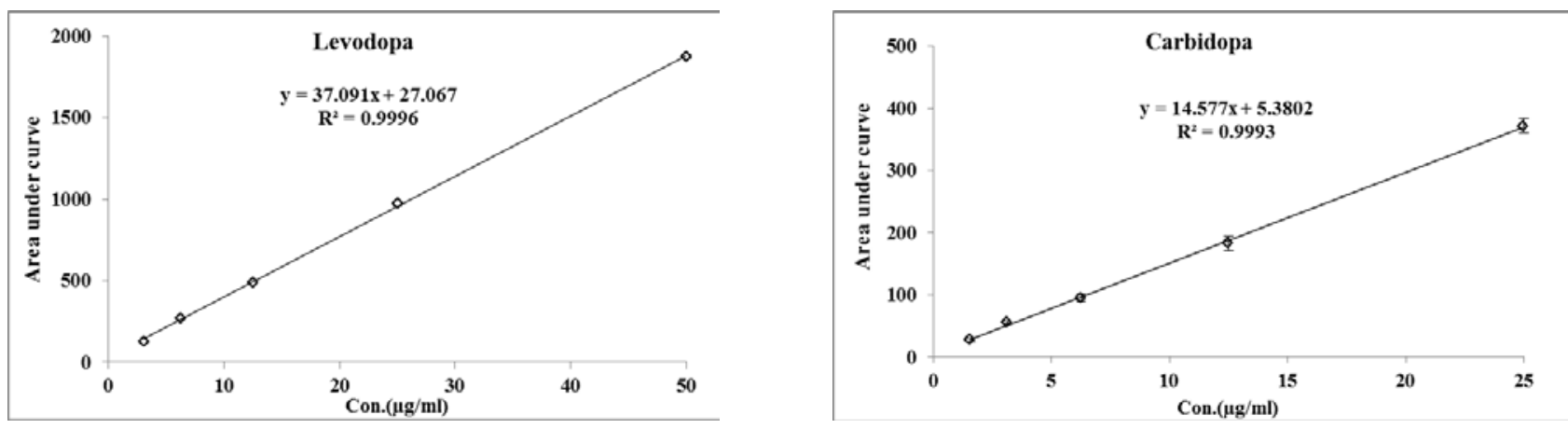

Fig. 2: Calibration curves of levodopa and carbidopa, (All values are mean \pm SD of five determinations)

Table 2: HPLC method validation results

\begin{tabular}{lll}
\hline & levodopa & carbidopa \\
\hline Intra-day precision\% & $98.1 \pm 1.9$ & $96.9 \pm 3.1$ \\
Inter-day precision\% & $98 \pm 2$ & $96.5 \pm 3.5$ \\
Accuracy \% & $96.4 \pm 3.6$ & $96.8 \pm 3.1$ \\
LOD $(\mu \mathrm{g} / \mathrm{ml})$ & 0.2 & 0.8 \\
LOQ $(\mu \mathrm{g} / \mathrm{ml})$ & 0.5 & 2.4 \\
\hline
\end{tabular}

All values are mean $\pm \mathrm{SD}$ of five determinations

\section{Tablets evaluation}

\section{In vitro disintegration time}

The US FDA recommends the most optimum FDT disintegration time is less than or equals to 1 minute $[10,26]$ whereas European Pharmacopeia sets a longer time of 3 min [10]. Considering the importance of FDTs disintegration time, the present study was focused on this parameter to select the optimized tablet. Tablets disintegration time are reported in table 3 . As it is presented in table 3, F1 and F2 which were produced using direct compression showed disintegration time higher than 2 min (both tablets friability was larger than 1\%), so granulation was used to prepare other formulations. Applying lactose showed no significant difference in disintegration time of F3. Using intra and extragranular disintegrant in F4 and F5 showed a significant decrease in disintegration time. F6 and F7 were prepared using extragranular disintegrant with different amounts of sorbitol. These two formulations were disintegrated in shorter time especially for F7 which was shorter than 1 minute. Statistical analysis showed that the disintegration time values of F8 and F9 formulations were significantly $\left({ }^{*} p<0.05\right)$ shorter than others which is related to the presence of excess Avicel PH 102 in both formulations. Avicel PH 102 is granular microcrystalline cellulose with excellent flow properties in formulations and can act as a disintegrant as well as a binder [28]. Porous morphology of Avicel PH 102 causes water be "wicked" through the capillary action and forces the tablet to break [30]. Therefore, F8 and F9 showed faster disintegration time which is acceptable for US FDA that recommends the most optimum FDT disintegration time less than or equals to 1 minute $[10,26]$

\section{Friability}

Friability results are reported in table 3. Friability of F1-F7 formulations was larger than 1 so they were not in an acceptable range. The resistance of particle bonding on the tablet surface to the effects of friction or abrasion is evaluated by tablet friability. FDTs friability must be less than 1\% [10]. F8 and F9 represented significantly $\left({ }^{*} p<0.05\right)$ different values which were in acceptable range. This observation could be also related to excess Avicel PH 102 application, since it can act as a binder $[28,30]$.

Table 3: Results of tablets quality evaluation

\begin{tabular}{|c|c|c|c|c|c|c|c|c|c|}
\hline & F1 & F2 & F3 & F4 & F5 & F6 & F7 & F8 & F9 \\
\hline Disintegration time (sec) & $148 \pm 3$ & $223 \pm 3$ & $210 \pm 3$ & $152 \pm 2$ & $151 \pm 5$ & $135 \pm 5$ & $49 \pm 2$ & $38 \pm 1$ & $30 \pm 2$ \\
\hline Friability (\%) & $>1$ & $>1$ & $>1$ & $>1$ & $>1$ & $>1$ & $>1$ & $0.45 \pm 0.02$ & $0.3 \pm 0.01$ \\
\hline
\end{tabular}

All values are mean \pm SD of three determinations

\section{Thickness and weight uniformity}

Thickness and weight of optimized F8 and F9 formulations were determined and results are reported in table 4. Considering USP-39, for tablets with weight higher than $324 \mathrm{mg}$, weight variation less than $5 \%$ is recommended. Therefore, weight variation of formulation F9 is in the acceptable range (4.9\%) while for F8, it is not accepted (10\%) [31].

\section{Hardness}

The compression force applied diametrically to crush optimized F8 and F9 formulations is reported in table 4. Tablet hardness is a parameter that not only represents the overall tablet resistance towards mechanical forces but also is associated with disintegration time. Although there are no pharmacopeia specifications for ODTs 
hardness, the acceptable hardness for FDTs is approximately lower $\left(3-5 \mathrm{~kg} / \mathrm{cm}^{2}\right)$ than conventional tablets [26].

\section{Drug content determination}

Levodopa and carbidopa amount was determined in optimized F8 and F9 formulations using validated HPLC method. Results are reported in table 4. Results confirm that it meets the criteria of USP39 [31].

\section{In vitro dissolution profile}

Considering tablets quality controls test, F9 showed the most acceptable results. Therefore, in vitro dissolution profile was studied for F9. Levodopa and carbidopa dissolution profile from FDTs is shown in fig. 3. As it is seen, more than $80 \%$ of levodopa and carbidopa was dissolved within first 5 min. Finally, $95 \pm 3 \%$ of levodopa and $97 \pm 2 \%$ of carbidopa was dissolved within $15 \mathrm{~min}$ which indicates that tablet complies to the International
Pharmacopoeia specifications for dissolution of the drug, that is, in the range of $85-110 \%[28,29]$.

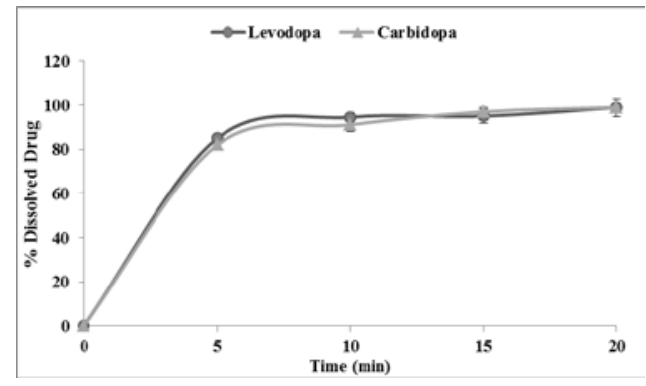

Fig. 3: In vitro dissolution of levodopa and carbidopa from F9, All values are mean \pm SD of three determinations

Table 4: Optimized tablets quality controls

\begin{tabular}{lll}
\hline & F8 & F9 \\
\hline Thickness (mm) & $3.10 \pm 0.05$ & $3.11 \pm 0.01$ \\
Average Weight (mg) & $330 \pm 36$ & $326.5 \pm 16$ \\
Hardness (Kg) & $2.91 \pm 0.4$ & $3.81 \pm 0.4$ \\
levodopa content (mg) & $96.8 \pm 3.2$ & $99 \pm 2.4$ \\
carbidopa content (mg) & $11.28 \pm 0.2$ & $10.5 \pm 0.4$ \\
\hline
\end{tabular}

All values are mean \pm SD of three determinations

\section{CONCLUSION}

A simple and rapid isocratic RP-HPLC method for simultaneous quantification of levodopa and carbidopa in the presence of different tablet excipients was developed and validated. Levodopa and carbidopa content and release from FDT were determined using the validated method. The optimized FDT showed acceptable hardness and was disintegrated within $30 \mathrm{sec}$. Levodopa and carbidopa released and dissolved within 5 min which was in an acceptable range. So the results indicated that this method is suitable for simultaneous quantification of levodopa and carbidopa in a pharmaceutical solid formulation.

\section{AUTHORS CONTRIBUTIONS}

All the author have contributed equally

\section{CONFLICTS OF INTERESTS}

All authors have none to declare

\section{REFERENCES}

1. S Sharma, S Lohan, RS Murthy. Formulation and characterization of intranasal mucoadhesive nano particulates and thermo-reversible gel of levodopa for brain delivery. Drug Dev Ind Pharm 2014;40:869-78.

2. J Goole, Amighi K. Levodopa delivery systems for the treatment of Parkinson's disease: an overview. Int J Pharm 2009;380:1-15.

3. R Bettini, D Acerbi, G Caponetti, R Musa, N Magi, P Colombo, et al. Influence of layer position on in vitro and in vivo release of levodopa methyl ester and carbidopa from three-layer matrix tablets. Eur J Pharm Biopharm 2002;53:227-32.

4. D Satyanarayana, K Keshavarao. Fast disintegrating films containing anastrozole as a dosage form for dysphagia patients. Arch Pharm Res 2012;35:2171-82.

5. K Chaitanya, S Velmurugan. Formulation and evaluation of levodopa effervescent floating tablets. In J Pharm Pharm Sci 2015;7:189-93.

6. S Mohammed, SK Sharma, K Kaucha, D Hiremath. Formulation and evaluation of flurbiprofen fast disintegrating tablets using natural superdisintegrants. Asian J Pharm Clin Res 2016;9:24754.

7. Vineet Bhardwaj, M Bansal, PK Sharma. Formulation and evaluation of fast dissolving tablets of amlodipine besylate using different super disintegrants and camphor as sublimating agent. Am-Eurasian J Sci Ress 2010;5:264-9.

8. Modasiya MK, Lala II, Prajapati BG, PVM, SDA. Design and characterization of fast disintegrating tablets of piroxicam.Int J PharmTech Res 2009;1:353-7.

9. J Goole, K Amighi. Levodopa delivery systems for the treatment of Parkinson's disease: an overview. Int J Pharm 2009;380:115.

10. HM Tawfeek, Faisal W. Enalapril maleate orally disintegrating tablets: Tableting and in vivo evaluation in hypertensive rats. Pharm Dev Technol 2018;23:496-503.

11. C Patil, S Das. Effect of various superdisintegrants on the drug release profile and disintegration time of lamotrigine orally disintegrating tablets. Afr J Pharm Pharmacol 2011;5:76-82.

12. S Alipour, S Akbari, F Ahmadi. Development and in vitro evaluation of fast-dissolving oral films of ondansetron hydrochloride. Trends Pharm Sci 2015;1:25-30.

13. $\mathrm{Y} \mathrm{Fu}, \mathrm{S}$ Yang, SH Jeong, $\mathrm{S}$ Kimura, $\mathrm{K}$ Park. Orally fast disintegrating tablets: developments, technologies, tastemasking and clinical studies. Crit Rev Ther Drug Carrier Syst 2004;21:433-76.

14. H Goel Rai, Parshuram Rana, Vikas Tiwary, Ashok K. Orally disintegrating systems: innovations in formulation and technology. Recent Pat Drug Delivery Formulation 2008;2:25874.

15. K Plachka, L Chrenkova, M Dousa, L Novakova. Development, validation and comparison of UHPSFC and UHPLC methods for the determination of agomelatine and its impurities. J Pharm Biomed Anal 2016;125:376-84.

16. O Vilhena Rde, FL Pontes, BM Marson, RP Ribeiro, KA de Carvalho, MA Cardoso, et al. A new HILIC-MS/MS method for the simultaneous analysis of carbidopa, levodopa, and its metabolites in human plasma. J Chromatogr B Anal Technol Biomed Life Sci 2014;967:41-9.

17. J Chi, Y Ling, R Jenkins, F Li. Quantitation of levodopa and carbidopa in rat plasma by LC-MS/MS: the key role of ionpairing reversed-phase chromatography. J Chromatogr B Anal Technol Biomed Life Sci 2017;1054:1-9.

18. FM Heliana, Douglas Pinto, Viviane de A, Nascimento Marlice, AS Marques, Fabio Amendoeira. Determination of levodopa in human plasma by high-performance liquid chromatographytandem mass spectrometry (HPLC-MS/MS): application to a bioequivalence study. Quim Nova 2013;36:171-6. 
19. K Chun, YH Lee, KE Lee, HS Gwaka. Design and evaluation of levodopa methyl ester intranasal delivery systems. Parkinson's Dis 2011:1:101-7.

20. PP Raut, SY Charde. Simultaneous estimation of levodopa and carbidopa by RP-HPLC using a fluorescence detector: its application to a pharmaceutical dosage form. Luminescence 2014;29:762-71.

21. P Bhatnagar, D Vyas, S Sinha, T Chakrabarti. Stability indicating HPLC method for simultaneous estimation of entacapone, levodopa and carbidopa in pharmaceutical formulation. J Chromatogr Sep Tech 2015;6. Doi: 10.4172/21577064.1000304

22. RF Donnelly. Stability of levodopa/carbidopa rectal suspensions. Hosp Pharm 2016;51:915-21.

23. K Chun, YH Lee, KE Lee, HS Gwaka. Design and evaluation of levodopa methyl ester intranasal delivery systems. J Parkinson's Dis 2011;1:101-7.

24. H Goel, P Rai, V Rana, AK Tiwary. Orally disintegrating systems: innovations in formulation and technology. Recent Pat Drug Delivery Formu 2008;2:258-74

25. S Alipour, Parhizkar, Elahehnaz Haleh, Farrahi, Ahmadi, Fatemeh. Formulation and in vitro evaluation of taste-masked fast disintegrating tablets of prednisolone. Lat Am J Pharm 2017;36:980-6.

26. L Winarti, L Ameliana, D Nurahmanto. Formula optimization of orally disintegrating tablet containing meloxicam nanoparticles. Indonesian J Pharm 2017;28:53-64

27. DM Shinkar, Pooja S, Aher Parag, D Kothawade, AD Maru. Formulation and invitro evaluation of fast dissolving tablet of verapamil hydrochloride. In J Pharm Pharm Sci 2018;10:93-9.

28. D Sharma. Formulation development and evaluation of fast disintegrating tablets of salbutamol sulphate for respiratory disorders. Int Scholar Res Notice Pharm 2013;2013:674507.

29. D Sharma, Singh G, Kumar D, Singh M. Formulation development and evaluation of fast disintegrating tablets of salbutamol sulphate, cetirizine hydrochloride in combined pharmaceutical dosage form: a new era in novel drug delivery for pediatrics and geriatrics. J Drug Delivery 2015;2015:1-10.

30. Nadia H Naiem, Ebtessam A Essa, GM Elmaghraby. Enhancing dissolution rate of indomethacin by in situ crystalization development of orally disintegrating tablets. In J Pharm Pharm Sci 2018;10:18-23.

31. USP Convention. U. S. Pharmacopeia-National Formulary. New York: United States Pharmacopeia; 2016. 